\title{
Detection of patients at high risk for nonocclusive mesenteric ischemia after cardiovascular surgery
}

\author{
Hiroshi Sato ${ }^{*}$, Masanori Nakamura ${ }^{2}$, Takeshi Uzuka ${ }^{2}$ and Mayo Kondo ${ }^{2}$
}

\begin{abstract}
Objectives: Nonocclusive mesenteric ischemia (NOMI) is a rare but life-threatening complication after cardiovascular surgery. Early diagnosis and treatment is essential for a chance to cure. The aim of this study is to identify the independent risk factors for NOMl based on the evaluation of 12 cases of NOMl after cardiovascular surgery.

Methods: We retrospectively analyzed 12 patients with NOMl and 674 other patients without NOMI who underwent cardiovascular surgery in our hospital. We reviewed the clinical data on NOMl patients, including their characteristics and the clinical course. In addition, we performed a statistical comparison of each factor from both NOMl and non-NOMl groups to identify the independent risk factors for NOMl.

Results: The median duration between the cardiac surgery and the diagnosis of NOMI was $14.0(10.3-20.3)$ days. The in-hospital mortality of NOMI patients was 75.0\%. Age $(p<0.05)$, peripheral arterial disease $(p<0$. 001), postoperative hemodialysis $(p<0.001)$, intraaortic balloon pump $(p<0.05)$, norepinephrine $(\mathrm{NOE})>0.10 \mathrm{Y}$ $(p<0.0001)$, percutaneous cardiopulmonary support $(p<0.001)$, sepsis $(p<0.05)$, loss of sinus rhythm $(p<0.05)$, prolonged ventilation $(p<0.0001)$, and resternotomy for bleeding $(p<0.05)$ showed significant differences between $\mathrm{NOMI}$ and non-NOMI groups. In the multivariate logistic regression model, prolonged ventilation [odds ratio $(\mathrm{OR})=18.1, p<0.001$ ] and $\mathrm{NOE}>0.10 \mu \mathrm{g} / \mathrm{kg} / \mathrm{min}(\mathrm{OR}=130.0, p<0.0001)$ were detected as independent risk factors for NOMl.

Conclusions: We have identified the risk factors for NOMI based on the evaluation of the 12 cases of NOMI after cardiovascular surgery. This result may be useful in predicting NOMI, which is considered difficult in clinical practice. For the patient with suspected of NOMI who has these risk factors, early CT scan and surgical exploration should be performed without delay.
\end{abstract}

Keywords: Nonocclusive mesenteric ischemia, Cardiovascular surgery, Risk model

\section{Introduction}

Nonocclusive mesenteric ischemia (NOMI) is a rare complication after cardiovascular surgery, and its incidence rates were reported to be about 0.4 to $9.0 \%$ [1-4]. Although the exact pathophysiology is currently unclear, it is assumed that the vasospasm of mesenteric artery results from the low perfusion during cardiopulmonary bypass $(\mathrm{CPB})$ or the various intra/postoperative therapeutic medications [5]. NOMI is a serious complication with a reported 30 to $90 \%$

\footnotetext{
* Correspondence: h.sato0229@gmail.com

${ }^{1}$ Department of Cardiovascular Surgery, Sapporo Medical University School of Medicine, S1W16, Chuo-ku, Sapporo 060-8543, Japan

Full list of author information is available at the end of the article
}

mortality rate $[2,4,5]$. Clinical signs, such as abdominal pain, vomiting, and hematochezia, can be seen but are not very specific. Also, the abnormal elevation of laboratory data has low specificity. The clinical sign is likely masked because the patient is often sedated and ventilated at the onset of NOMI; therefore, the diagnosis of NOMI is frequently difficult and delayed. In computed tomography (CT) scan findings, absence of bowel wall enhancement, pneumatosis intestinalis, and portal venous gas are specific radiological signs but do not necessarily appear in ischemic conditions. Therefore, constant monitoring of the possibility of intestinal ischemia for the high-risk patient and surgical

(C) The Author(s). 2018 Open Access This article is distributed under the terms of the Creative Commons Attribution 4.0 International License (http://creativecommons.org/licenses/by/4.0/), which permits unrestricted use, distribution, and reproduction in any medium, provided you give appropriate credit to the original author(s) and the source, provide a link to the Creative Commons license, and indicate if changes were made. The Creative Commons Public Domain Dedication waiver (http://creativecommons.org/publicdomain/zero/1.0/) applies to the data made available in this article, unless otherwise stated. 
exploration without delay are the only ways for the improvement of survival rate. [6-8]

However, there are few studies that have detected the risk factor of NOMI after cardiovascular surgery [2, 5]. In this study, we reviewed the clinical data of 12 cases of NOMI after cardiovascular surgery in our hospital. Then, we investigated each factor between the two groups and detected the independent risk factors for NOMI.

\section{Materials and methods \\ Patients}

From March 1, 2010 to December 31, 2018, among the patients who underwent cardiovascular surgery in our institution, we conducted a retrospective case-control study for $12(1.74 \%)$ patients who developed NOMI after surgery and 674 (98.3\%) other patients. We also included emergent surgical cases and off-pump cases. Excluded cases were the patients with type A aortic dissection who had mesenteric ischemia before surgery, thoracic endovascular aortic repair, and pericardial fenestration.

\section{Diagnosis of NOMI}

After cardiovascular surgery, the patients with suspected NOMI because of abdominal distension with absence of bowel sounds, acute abdominal pain, vomiting, hematochezia, or abnormal laboratory data underwent urgent abdominal CT scans. NOMI was diagnosed by the confirmation of the presence of ischemic bowel signs (absence of bowel wall enhancement, pneumatosis intestinalis, or portal venous gas; (Fig. 1) without the occlusion or thrombus of the superior mesenteric artery in the CT scan findings and undisputed mesenteric ischemia by surgical exploration. All radiological signs in the $\mathrm{CT}$ scans were reviewed by the radiologist. The $\mathrm{CT}$ scan and surgical laparotomy were performed by the judgment of each operator to confirm the diagnosis.

\section{Definition of each analyzed data}

Valve surgery included aortic valve replacement /aortic valve plasty, mitral valve replacement (MVR)/mitral valve plasty (MVP), and tricuspid annulus plasty. Thoracic aortic surgery included ascending aortic replacement (AAR)/total arch replacement (TAR)/hemi-arch replacement, and aortic root replacement/remodeling. Each analyzed factor was defined using the following criteria. Norepinephrine $(\mathrm{NOE})>0.10 \mu \mathrm{g} / \mathrm{kg} / \mathrm{min}$ was defined as using NOE more than $0.10 \mu \mathrm{g} / \mathrm{kg} / \mathrm{min}$ for more than $1 \mathrm{~h}$ after surgery. Low output syndrome (LOS) was defined as using mechanical support, that is, intraaortic balloon pump (IABP) support and percutaneous cardiopulmonary support (PCPS). Prolonged ventilation was defined as mechanical ventilation time after surgery of more than $24 \mathrm{~h}$. Loss of sinus rhythm was defined as the documented loss of sinus rhythm for at least $6 \mathrm{~h}$ after surgery. Hyperlactatemia was defined as having a serum lactate level of $>5.0 \mathrm{mmol} / \mathrm{L}$.

\section{Statistical analysis}

Statistical analysis was performed using Mann-Whitney $U$ test for continuous variables and $\chi^{2}$ test and Fisher's exact test for categorical variables. Variables found associated with $P<0.05$ in the univariate analysis were entered into a multivariate logistic regression analysis, using the stepwise selection method, to identify the factors independently associated with a definite risk factor of NOMI. All results were expressed as median (interquartile range). Statistical significance was set at $P<0.05$ (two-sided). All data analyses were performed using the statistical program $\mathrm{R}$ version 3.2.1 ( $\mathrm{R}$ Foundation for Statistical Computing, http://www.r-project.org/).

\section{Results}

Among patients who underwent cardiovascular surgery in our institution, $12(1.74 \%)$ cases developed NOMI. The background of NOMI cases, including patient characteristics, surgery type, and state at the onset of
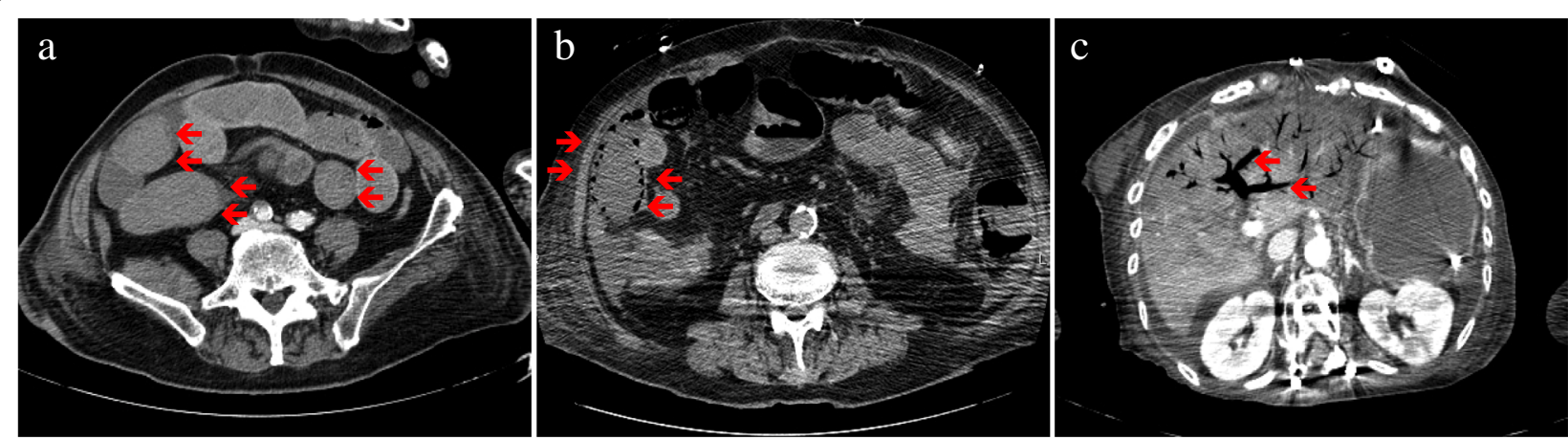

Fig. 1 Red arrows indicate the $C T$ findings of the diagnosis of NOMI in each images: a absence of bowel wall enhancement, $\mathbf{b}$ pneumatosis intestinalis, and $\mathbf{c}$ portal venous gas 
NOMI, is displayed in Table 1 . The mean age of patients was $74.67 \pm 7.6$ years, and $8(66.7 \%)$ patients were male and $4(33.3 \%)$ patients were female. The details of the cardiovascular surgery were 5 (41.7\%) off-pump coronary artery bypass graft surgery (OPCABG), 4 (33.3\%) CABG, 2 (16.7\%) valve surgery, and 2 (16.7\%) thoracic aortic surgery. As initial symptoms and findings of NOMI, abdominal pain, vomiting, fever, hematochezia, hypotension, or hyperlactatemia were noted. At the onset of NOMI, 8 of 12 cases were under sedation due to mechanical ventilation. Nine $(75.0 \%)$ cases died in the hospital and $3(25.0 \%)$ survived. The median duration between the cardiovascular surgery and the onset of NOMI was $14.0(10.3-20.3)$ days, and the onset of NOMI for 6 of 12 cases (50.0\%) was between 15 and 20 days (Fig. 2).

NOE $>0.10 \mu \mathrm{g} / \mathrm{kg} / \mathrm{min}$ was used for 7 of 12 cases within $24 \mathrm{~h}$ before the onset of NOMI. Cases 5 to 7 and 11 were in a state of LOS; furthermore, case 11 also had sepsis and underwent hemodialysis. Cases 5 and 7 underwent hemodialysis too, and Case 6 did not. Cases 1,8 , and 9 were not at a state of LOS and had sepsis but underwent hemodialysis while using NOE. NOE was not used for Cases 2 to 4, 10, and 12. Cases 2 and 4 had sepsis, and Case 12 was at a state of LOS and underwent hemodialysis. Cases 3 and 10 were not in any condition. As initial findings/symptoms, 7 of 12 cases showed hyperlactatemia. In others, 1 hypotension, 2 abdominal pain, 1 vomiting, and 1 hematochezia were found.

Between NOMI and non-NOMI groups, pre/intra/postoperative factors were summarized and subjected to statistical comparison (Tables 2 and 3). There was a significant difference in 10 factors: age $(p<0.05)$, peripheral arterial disease (PAD; $p<0.001)$, postoperative hemodialysis $(p<$ $0.001)$, IABP $(p<0.01), \mathrm{NOE}>0.10 \mu \mathrm{g} / \mathrm{kg} / \mathrm{min}(p<0.0001)$, PCPS $(p<0.0001)$, sepsis $(p<0.01)$, loss of sinus rhythm $(p$ $<0.01)$, prolonged ventilation $(p<0.0001)$, and resternotomy for bleeding $(p<0.01)$. Finally, these 10 factors were introduced for the multivariate logistic regression model as covariates and adjusted odds ratio (OR) were calculated. As a result, prolonged ventilation $(\mathrm{OR}=18.1, p<0.001)$ and $\mathrm{NOE}>0.10 \quad \mu \mathrm{g} / \mathrm{kg} / \mathrm{min} \quad(\mathrm{OR}=130.0, \quad p<0.0001) \quad$ were detected as independent risk factors for NOMI (Table 4).

Further analysis for these two variables showing significant difference in the multivariate logistic model has proceeded. Among the total 26 cases corresponding to $\mathrm{NOE}>0.10 \mu \mathrm{g} / \mathrm{kg} / \mathrm{min}$, total quantity $(\mu \mathrm{g} / \mathrm{kg}$ ), duration (h), and maximum dose of $\mathrm{NOE}(\mu \mathrm{g} / \mathrm{kg} / \mathrm{min})$ were statistically compared between NOMI (9 cases) and non-NOMI (17 cases) groups. Similarly, among the total 117 cases corresponding to prolonged ventilation, maximum PEEP $\left(\mathrm{cmH}_{2} \mathrm{O}\right)$, total ventilation time $(\mathrm{h})$, and index calculated from PEEP * ventilation time/body weight (BW) $\left(\mathrm{cmH}_{2} \mathrm{O}\right.$ * $\mathrm{h} / \mathrm{kg}$ ) were statistical compared between NOMI (9 cases) and non-NOMI (108 cases) groups. As a result, all variables were higher in the NOMI group, but no significant difference was found between the two groups (Table 5).

\section{Discussion}

NOMI is a rare but life-threatening complication after cardiovascular surgery. Although it is assumed to be the result of microcirculatory alterations initiated during $\mathrm{CPB}$ and the vasospasm of mesenteric artery, its pathomechanism is as yet unclear. It is considered

Table 1 Background of 12 NOMl patients

\begin{tabular}{|c|c|c|c|c|c|c|c|c|c|c|c|c|}
\hline \multirow[t]{2}{*}{ No } & \multirow[t]{2}{*}{ Age } & \multirow[t]{2}{*}{ Sex } & \multirow[t]{2}{*}{ Surgery } & \multirow[t]{2}{*}{ Emergency } & \multirow{2}{*}{$\begin{array}{l}\text { Initial } \\
\text { symptoms/findings }\end{array}$} & \multirow{2}{*}{$\begin{array}{l}\text { Duration } \\
\text { between Surgery } \\
\text { and NOMI(days) }\end{array}$} & \multicolumn{5}{|c|}{ Patient state at the onset of $\mathrm{NOMI}$} & \multirow[t]{2}{*}{ Result } \\
\hline & & & & & & & $\begin{array}{l}\mathrm{NOE}>0.10 \\
\mu \mathrm{g} / \mathrm{kg} / \mathrm{min}\end{array}$ & LOS & Sepsis & $\mathrm{HD}$ & Sedation & \\
\hline 1 & 83 & Male & TAR & No & Hyperlactatemia & 13 & Yes & No & No & Yes & Yes & Death \\
\hline 2 & 81 & Male & OPCABG & No & Hematochezia & 64 & No & No & Yes & Yes & Yes & Death \\
\hline 3 & 67 & Male & OPCABG & No & Abdominal pain & 13 & No & No & No & No & No & Survival \\
\hline 4 & 66 & Male & OPCABG & No & Abdominal pain & 34 & No & No & Yes & No & No & Survival \\
\hline 5 & 77 & Female & AAR & Yes & Hyperlactatemia & 17 & Yes & Yes & No & Yes & Yes & Death \\
\hline 6 & 81 & Male & CABG & No & Hyperlactatemia & 30 & Yes & Yes & No & No & No & Death \\
\hline 7 & 86 & Male & OPCABG & Yes & Hyperlactetamia & 8 & Yes & Yes & No & Yes & Yes & Death \\
\hline 8 & 69 & Female & OPCABG & No & Hyperlactetamia & 11 & Yes & No & No & Yes & Yes & Death \\
\hline 9 & 67 & Female & CABG & No & Hyperlactatemia & 2 & Yes & No & No & Yes & Yes & Death \\
\hline 10 & 76 & Female & MVP, TAP & No & Vomiting & 15 & No & No & No & No & No & Survival \\
\hline 11 & 79 & Male & CABG, MVR & No & Hypotension & 15 & Yes & Yes & Yes & Yes & Yes & Death \\
\hline 12 & 64 & Male & CABG & Yes & Hyperlactatemia & 5 & No & Yes & No & Yes & Yes & Death \\
\hline
\end{tabular}

NOMI non-occlusive mesenteric ischemia, NOE norepinephrine, LOS low output syndrome, HD hemodialysis, TAR Total Arch Aortic Replacement, OPCABG off-pump coronary artery bypass graft surgery, $A A R$ Ascending Aortic Replacement, CABG coronary artery bypass graft surgery, MVP mitral valve plasty, TAP tricuspid annuloplasty, MVR mitral valve replacement 


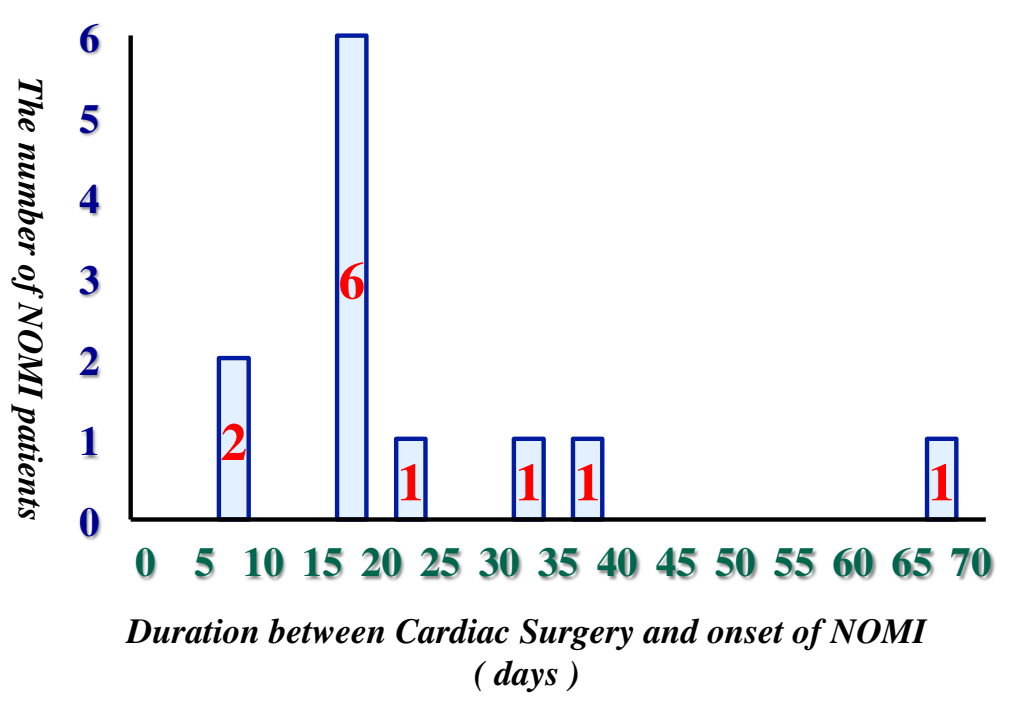

Fig. 2 Relationship of the number of NOMI patients and duration between cardiovascular surgery and onset of NOMl

that it is caused by not only the invasion with cardiovascular surgery itself but also various factors such as the exacerbation of general conditions and using each therapeutic medication for it after surgery $[8,9]$. In previous studies, its incidence rate was reported to be about 0.4 to $9.0 \%$, and mortality was 30 to $93 \%$ [1-5]. In the present study, the incidence rate was $1.91 \%$ and in-hospital mortality was $75.0 \%$, which was a similar result.

We have reviewed the clinical data of 12 NOMI cases and assumed the mechanism and the cause at the onset. Almost all the patients used high-dose NOE after surgery because of their condition of LOS, sepsis, or need for hemodialysis. When we investigated their clinical course in detail, it turned out that there were several factors that developed in combination at the onset of NOMI. In some cases, NOE was dose up just before the onset of NOMI due to the deterioration of LOS and sepsis or at the beginning of dehydration by hemodialysis. The effect of
NOE, which induces vasoconstriction, increases resistance in peripheral splanchnic vessels, and stimulates $\beta$ receptors in a dose-dependent manner to increase intestinal oxygen consumption, is likely to cause mesenteric ischemia $[2,5,10]$. As the result of the multivariate analysis of this study, the use of NOE $>0.10 \mu \mathrm{g} / \mathrm{kg} / \mathrm{min}$ has shown significantly high OR and may have a strong association with the development of NOMI. It is difficult to detect the definite cause of NOMI because this cannot be explained by only the use of NOE and several factors may be related in complicated. However, the status of NOE and the presence of LOS, sepsis, and hemodialysis, which may be the reason for the use of NOE, can be the important factor in the pathogenic mechanism of NOMI.

Selective catheter angiography for mesenteric artery remains the gold standard for the diagnosis of NOMI. In previous studies, angiography was performed for all patients with suspected mesenteric ischemia because of the decreased intestinal peristalsis after cardiovascular

Table 2 Preoperative characteristics

\begin{tabular}{llll}
\hline Variables & NOMI $(n=12)$ & Non-NOMI $(n=674)$ & $P$ value \\
\hline Age, median (IQR) (years) & $67(64-74.5)$ & $63(29-70)$ & $<0.05$ \\
Age $>75, \mathrm{n}(\%)$ & $7(58.3)$ & $193(28.1)$ & $<0.05$ \\
Sex: Male, $\mathrm{n}(\%)$ & $8(66.7)$ & $430(62.7)$ & 0.99 \\
COPD, $\mathrm{n}(\%)$ & $2(16.7)$ & $138(20.4)$ & 0.95 \\
Diabetes, $\mathrm{n}(\%)$ & $5(41.7)$ & $248(36.9)$ & 0.77 \\
Hemodialysis, $\mathrm{n}(\%)$ & $4(33.3)$ & $115(16.8)$ & 0.138 \\
Hypertension, $\mathrm{n}(\%)$ & $8(66.7)$ & $421(61.4)$ & 0.775 \\
Peripheral Arterial Disease, $\mathrm{n}(\%)$ & $5(41.7)$ & $43(6.3)$ & $<0.001$ \\
Stroke, $\mathrm{n}(\%)$ & $1(8.3)$ & $20(2.9)$ & 0.314 \\
\hline
\end{tabular}

IQR interquartile range, COPD chronic obstructive pulmonary disease 
Table 3 Operative and postoperative characteristics and in-hospital mortality

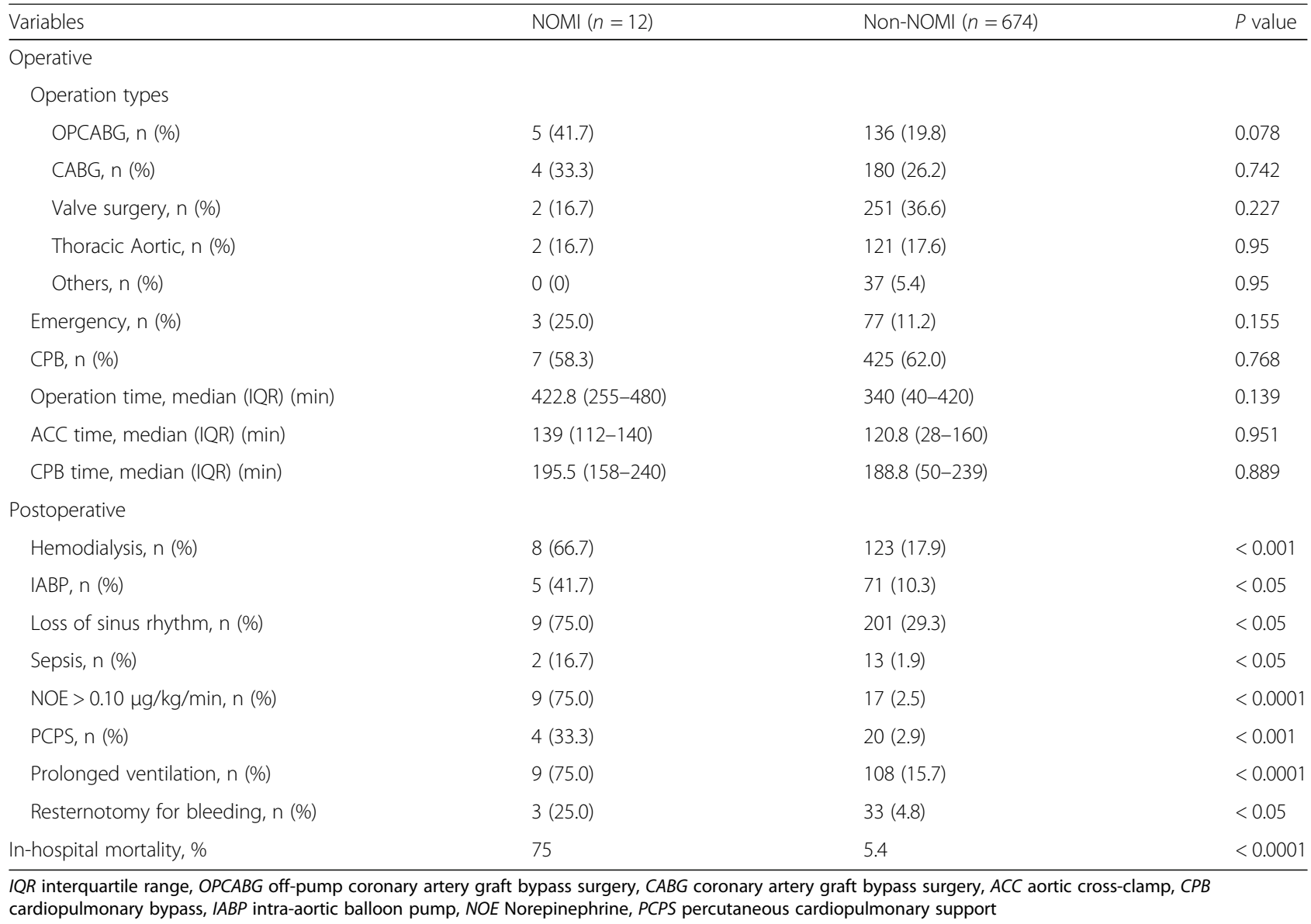

surgery [2, 3]. In addition to the detection of the mesenteric arterial vasospasm, the inserted catheter allows the selective mesenteric intraarterial infusion of vasodilatative drugs. Using this diagnosis and treatment method, the result of low mortality was reported [3]. However, there were also reported cases that required surgical exploration and intestinal resection eventually, so its therapeutic effects are not clear yet $[3,11]$. Angiography is an invasive procedure that cannot be applied for all patients with suspected symptoms.

In CT scan findings, pneumatosis intestinalis and portal venous gas are specific radiological signs, but both may be seen as nonischemic conditions [12]. Hasan et al. have reported that, among 26 patients with suspected NOMI

Table 4 Univariate and multivariate logistic regression model

\begin{tabular}{|c|c|c|c|c|c|c|}
\hline \multirow[t]{2}{*}{ Risk factor } & \multicolumn{3}{|c|}{ Univariate analysis } & \multicolumn{3}{|c|}{ Multivariate analysis } \\
\hline & $\overline{\mathrm{OR}}$ & $95 \% \mathrm{Cl}$ & $P$ Value & Adjusted OR & $95 \% \mathrm{Cl}$ & $P$ Value \\
\hline Age $>75$ & 3.52 & $1.10-11.20$ & $<0.05$ & & & \\
\hline Peripheral Arterial Disease & 10.30 & $3.12-33.80$ & $<0.001$ & & & \\
\hline Postoperative hemodialysis & 8.88 & $2.63-30.00$ & $<0.001$ & & & \\
\hline IABP & 5.65 & $1.75-18.30$ & $<0.01$ & & & \\
\hline Loss of sinus rhythm & 6.92 & $1.85-25.80$ & $<0.01$ & & & \\
\hline Sepsis & 10.10 & $1.98-50.90$ & $<0.05$ & & & \\
\hline $\mathrm{NOE}>0.10 \mu \mathrm{g} / \mathrm{kg} / \mathrm{min}$ & 52.40 & $15.00-183.00$ & $<0.0001$ & 130.0 & $21.4-921.0$ & $<0.0001$ \\
\hline PCPS & 15.70 & $4.34-56.60$ & $<0.001$ & & & \\
\hline Prolonged ventilation & 15.10 & $4.02-56.70$ & $<0.0001$ & 18.1 & $6.64-388.0$ & $<0.001$ \\
\hline Resternotomy for bleeding & 7.55 & $1.93-29.60$ & $<0.05$ & & & \\
\hline
\end{tabular}


Table 5 NOE and ventilation factors of NOMl and non-NOMI groups

\begin{tabular}{|c|c|c|c|}
\hline Variables & $\operatorname{NOMI}(n=9)$ & Non-NOMI $(n=17)$ & $P$ value \\
\hline \multicolumn{4}{|l|}{ NOE factor } \\
\hline Quantity, median (IQR) ( $\mu \mathrm{g} / \mathrm{kg})$ & $1237.2(853.6-1850.1)$ & $559.6(331-2821.7)$ & 0.403 \\
\hline Maximum dose, median (IQR) ( $\mu \mathrm{g} / \mathrm{kg} / \mathrm{min})$ & $0.43(0.28-0.75)$ & $0.37(0.21-0.56)$ & 0.219 \\
\hline Duration, median (IQR) (h) & $106.3(38-146)$ & $81(37.3-208.3)$ & 0.9 \\
\hline Variables & $\operatorname{NOMI}(n=9)$ & Non-NOMI $(n=108)$ & $P$ value \\
\hline \multicolumn{4}{|l|}{ Ventilation factor } \\
\hline Maximum PEEP, median (IQR) $(\mathrm{cmH} 2 \mathrm{O})$ & $10(10-14)$ & $10(8-10)$ & 0.157 \\
\hline Total ventilation time, median (IQR) (h) & $226(116-308)$ & $87(51.5-189.5)$ & 0.077 \\
\hline $\mathrm{PEEP} *$ ventilation time/BW index, median (IQR) $\left(\mathrm{cmH}_{2} \mathrm{O} * \mathrm{~h} / \mathrm{kg}\right)$ & $24.2(15.6-36.9)$ & $11.7(6.5-28.7)$ & 0.051 \\
\hline
\end{tabular}

$I Q R$ interquartile range, NOE Norepinephrine, PEEP positive end expiratory pressure, $B W$ body weight

from CT scan findings, 13 (50\%) patients have confirmed bowel ischemia by surgical exploration and definite diagnosis of NOMI [7]. They have indicated the inaccuracy of the diagnosis by CT scan findings and necessity of surgical exploration without delay. A surgical exploration is only reliable way to provide an accurate assessment of bowel viability and necrotic sections requiring segmental intestinal resection $[7,10,12]$. Therefore, when we suspected the presence of intestinal ischemia from the comprehensive evaluation of the clinical course and laboratory data, we make it a rule to perform the CT scan and surgical exploration without hesitation.

In previous studies, the analysis for each laboratory data to predict and detect NOMI has been reported. In particular, there are several studies that indicate the elevation of lactate at the onset of NOMI [2, 3, 5, 13]. However, because hyperlactatemia can be found in various conditions, it is difficult to distinguish whether the cause of hyperlactatemia is NOMI or other factors $[6,14]$. Simon et al. provided the results of analyzed laboratory data including lactate, creatine kinase, and lactate dehydrogenase isozyme. There were no significant differences between confirmed and negative diagnoses among patients with suspected NOMI [12].

In the present study, 7 of 12 cases were diagnosed with NOMI with hyperlactenemia as initial findings. However, because the elevation of serum lactate level was thought to be reflected irreversible and lethal mesenteric ischemia, all of 7 cases having shown hyperlactatemia could not be saved. When the serum lactate level has been elevated, it is highly likely to be too late for cure. Thus, lactate has lower usefulness for early diagnosis, and rather nonspecific gastrointestinal symptoms such as abdominal pain or vomiting may be more useful. Also, among the 12 cases in this study, 3 cases who survived were diagnosed early from subjective symptoms such as abdominal pain, not objective laboratory data. However, it was difficult to find subjective symptoms early because almost all
NOMI patients were under sedation for mechanical ventilation. Such a situation is often seen at the onset of NOMI and may impede the early diagnosis.

Although there have been several studies that reported predictive factors for occlusive mesenteric ischemia after cardiovascular surgery or NOMI during intensive care, only a few focused on NOMI after cardiovascular surgery [2, 5, 13-19]. As the result of this analysis, NOE $>0.10 \mu \mathrm{g} / \mathrm{kg} /$ min and prolonged ventilation were identified as isolate risk factors for the onset of NOMI. The prolonged ventilation may be the cause of mesenteric ischemia because of peripheral hypoperfusion under sustained sedation and long-term bedridden condition [2, 15-18]. It is also suggested that PEEP decreases mesenteric blood flow and lung injury by mechanical ventilation can spread the pulmonary inflammation to distant organs [20,21].

In this present study, we have further analyzed the use of NOE and prolonged ventilation as independent risk factors for NOMI, focusing on corresponding cases. This is because we considered that the definite cutoff value of NOE and ventilation factor can be further effective to predict the incidence of NOMI. For the NOE factor, total quantity, duration, and maximum dose of $\mathrm{NOE}$ were analyzed. For the prolonged ventilation factor, maximum PEEP, total ventilation time, and index calculated from PEEP * ventilation time/ $\mathrm{BW}$ were analyzed. However, between NOMI and non-NOMI groups corresponding to each factor, there were no significant differences and definite cutoff value could not be calculated in both factors (Table 5). This is because each patient status after cardiovascular surgery was individually different, and the threshold of the onset of mesenteric ischemia was varied depending on the patient's general conditions. For example, even between patients who used the same high dose of NOE, there are several factors related to intestinal blood flow. Consequently, the actual dose that can be the cause of mesenteric ischemia for each case is not expected to be the same. If insufficient circulatory dynamics or severe arteriosclerotic change is present, 
mesenteric ischemia can be caused by an even lower dose of NOE. The same applies to the ventilation factor. Hence, the use of high dose of NOE and prolonged ventilation are important for the onset of NOMI; however, it is very difficult to detect the definite and detailed cutoff value.

There are several limitations to our study. Because this is a retrospective and single-center database study, the reliability of each data is insufficient. In particular, suspecting the onset of NOMI and judging to perform the CT scan and laparotomy are dependent on the surgeon's judgment. Furthermore, we have detected the independent risk factors from the multivariate regression model, but statistical reliability does not seem to be high because of a small number of NOMI cases.

There may be patients with mesenteric ischemia who were excluded from the NOMI group as we did not confirm mesenteric ischemia with surgical exploration. We confirmed no occlusion of mesenteric vessels from the CT scan findings instead of the selective mesenteric angiography. The cause of mesenteric ischemia may have been the occlusion or thrombosis.

\section{Conclusions}

We have reviewed 12 cases who developed NOMI after cardiovascular surgery in our institution. Rapid prediction and diagnosis are essential to lower mortality. However, they are very difficult in practice because almost all patients with NOMI were under sedation and mechanical ventilated; thus, their prognosis was extremely poor.

In the multivariate logistic regression model, we have detected the use of NOE $>0.10 \mu \mathrm{g} / \mathrm{kg} / \mathrm{min}$ and prolonged ventilation as independent risk factors of NOMI after cardiovascular surgery. In particular, we consider that the status of NOE and the presence of the factor, which can be the reason for the use of NOE, are strongly associated with the onset of NOMI. For the patient with suspected NOMI who have these risk factors, early CT scan and surgical exploration should be performed without delay.

\section{Abbreviations}

AAR: Ascending aortic replacement; BW: Body weight; CPB: Cardiopulmonary bypass; CT: Computed tomography; IABP: Intraaortic balloon pump; LOS: Low output syndrome; MVP: Mitral valve plasty; MVR: Mitral valve replacement; NOE: Norepinephrine; NOMI: Nonocclusive mesenteric ischemia; OPCABG: Off-pump coronary artery bypass graft surgery; OR: Odds ratio; PCPS: Support and percutaneous cardiopulmonary support; SD: Standard deviation; TAR: Total arch replacement

\section{Acknowledgements}

Not applicable.

Funding

Not applicable.

Availability of data and materials Not applicable.
Authors' contributions

All authors read and approved the final manuscript.

Ethical approval and consent to participate

Not applicable.

Consent for publication

Not applicable.

Competing interests

The authors declare that they have no competing interests.

\section{Publisher's Note}

Springer Nature remains neutral with regard to jurisdictional claims in published maps and institutional affiliations.

\section{Author details}

'Department of Cardiovascular Surgery, Sapporo Medical University School of Medicine, S1W16, Chuo-ku, Sapporo 060-8543, Japan. ${ }^{2}$ Department of Cardiovascular Surgery, Sapporo City General Hospital, N11W13, Chuo-ku, Sapporo 060-8604, Japan.

Received: 18 July 2018 Accepted: 5 November 2018

Published online: 16 November 2018

\section{References}

1. Hajjar LA, Vincent JL, Barbosa Gomes Galas FR, Rhodes A, Landoni G, Osawa $E A$, et al. Vasopressin versus norepinephrine in patients with Vasoplegic shock after cardiac surgery: the VANCS randomized controlled trial. Anesthesiology. 2017;126:85-93.

2. Groesdonk HV, Klingele M, Schlempp S, Bomberg H, Schmied W, Minko P, et al. Risk factors for nonocclusive mesenteric ischemia after elective cardiac surgery. J Thorac Cardiovasc Surg. 2013;145:1603-10.

3. Klotz S, Vestring T, Rötker J, Schmidt C, Scheld HH, Schmid C, et al. Diagnosis and treatment of nonocclusive mesenteric ischemia after open heart surgery. Ann Thorac Surg. 2001;72:1583-6.

4. Suguru W, Genya Y, Azumi H, Shunichi K. Early diagnosis and therapy of non-occlusive mesenteric ischemia after open heart surgery. Jpn J Cardiovasc Surg. 2008:37:69-73.

5. Lim JY, Kim JB, Jung SH, Choo SJ, Chung CH, Lee JW. Risk factor analysis for nonocclusive mesenteric ischemia following cardiac surgery: a case-control study. Medicine (Baltimore). 2017;9:e8029.

6. Edwards M, Sidebotham D, Smith M, Leemput JV, Anderson B. Diagnosis and outcome from suspected mesenteric ischaemia following cardiac surgery. Anaesth Intensive Care. 2005;33:210-7.

7. Hasan S, Ratnatunga C, Lewis CT, Pillai R. Gut ischaemia following cardiac surgery. Interact Cardiovasc Thorac Surg. 2004;3:475-8.

8. Ghosh S, Roberts N, Firmin RK, Jameson J, Spyt TJ. Risk factors for intestinal ischaemia in cardiac surgical patients. Eur J Cardiothorac Surg. 2002;21:411-6.

9. Trompeter M, Brazda T, Remy CT, Vestring T, Reimer P. Non-occlusive mesenteric ischemia: etiology, diagnosis, and interventional therapy. Eur Radiol. 2002;12:1179-87.

10. O'Dwyer C, Woodson LC, Conroy BP, Lin CY, Deyo DJ, Uchida T, et al. Regional perfusion abnormalities with phenylephrine during normothermic bypass. Ann Thorac Surg. 1997;63:728-35.

11. Mitsuyoshi A, Obama K, Shinkura N, Ito T, Zaima M. Survival in nonocclusive mesenteric ischemia: early diagnosis by multidetector row computed tomography and early treatment with continuous intravenous high-dose prostaglandin E(1). Ann Surg. 2007;246:229-35.

12. Bourcier S, Oudjit A, Goudard G, Charpentier J, Leblanc S, Coriat R. Diagnosis of non-occlusive acute mesenteric ischemia in the intensive care unit. Ann Intensive Care. 2016;6:112.

13. Quiroga B, Verde E, Abad S, Vega A, Goicoechea M, Reque J, et al. Detection of patients at high risk for non-occlusive mesenteric ischemia in hemodialysis. J Surg Res. 2013;180:51-5.

14. Abboud B, Daher R, Boujaoude J. Acute mesenteric ischemia after cardio-pulmonary bypass surgery. World J Gastroenterol. 2008;14: 5361-70.

15. Spotnitz WD1, Sanders RP, Hanks JB, Nolan SP, Tribble CG, Bergin JD et al. General surgical complications can be predicted after cardiopulmonary bypass. Ann Surg 1995;22:489-496. 
16. Aouifi A, Piriou V, Bastien O, Joseph P, Blanc P, Chiari P, et al. Severe digestive complications after heart surgery using extracorporeal circulation. Can J Anaesth. 1999;46:114-21.

17. D'Ancona G, Baillot $R$, Poirier B, Dagenais F, de lbarra Jl, Bauset $R$, et al. Determinants of gastrointestinal complications in cardiac surgery. Tex Heart Inst J. 2003;30:280-5.

18. Chaudhuri N, James J, Sheikh A, Grayson AD, Fabri BM. Intestinal ischaemia following cardiac surgery: a multivariate risk model. Eur J Cardiothorac Surg. 2006;29:971-7.

19. Rastan AJ, Tillmann E, Subramanian S, Lehmkuhl L, Funkat AK, Leontyev S, et al. Visceral arterial compromise during intra-aortic balloon counterpulsation therapy. Circulation. 2010;122:92-9.

20. Love R, Choe E, Lippton H, Flint L, Steinberg S. Positive end-expiratory pressure decreases mesenteric blood flow despite normalization of cardiac output. J Trauma. 1995;39:195-9.

21. Badenes R, Lozano A, Belda FJ. Postoperative pulmonary dysfunction and mechanical ventilation in cardiac surgery. Crit Care Res Pract 2015;2015:420513

Ready to submit your research? Choose BMC and benefit from:

- fast, convenient online submission

- thorough peer review by experienced researchers in your field

- rapid publication on acceptance

- support for research data, including large and complex data types

- gold Open Access which fosters wider collaboration and increased citations

- maximum visibility for your research: over $100 \mathrm{M}$ website views per year

At BMC, research is always in progress.

Learn more biomedcentral.com/submissions 